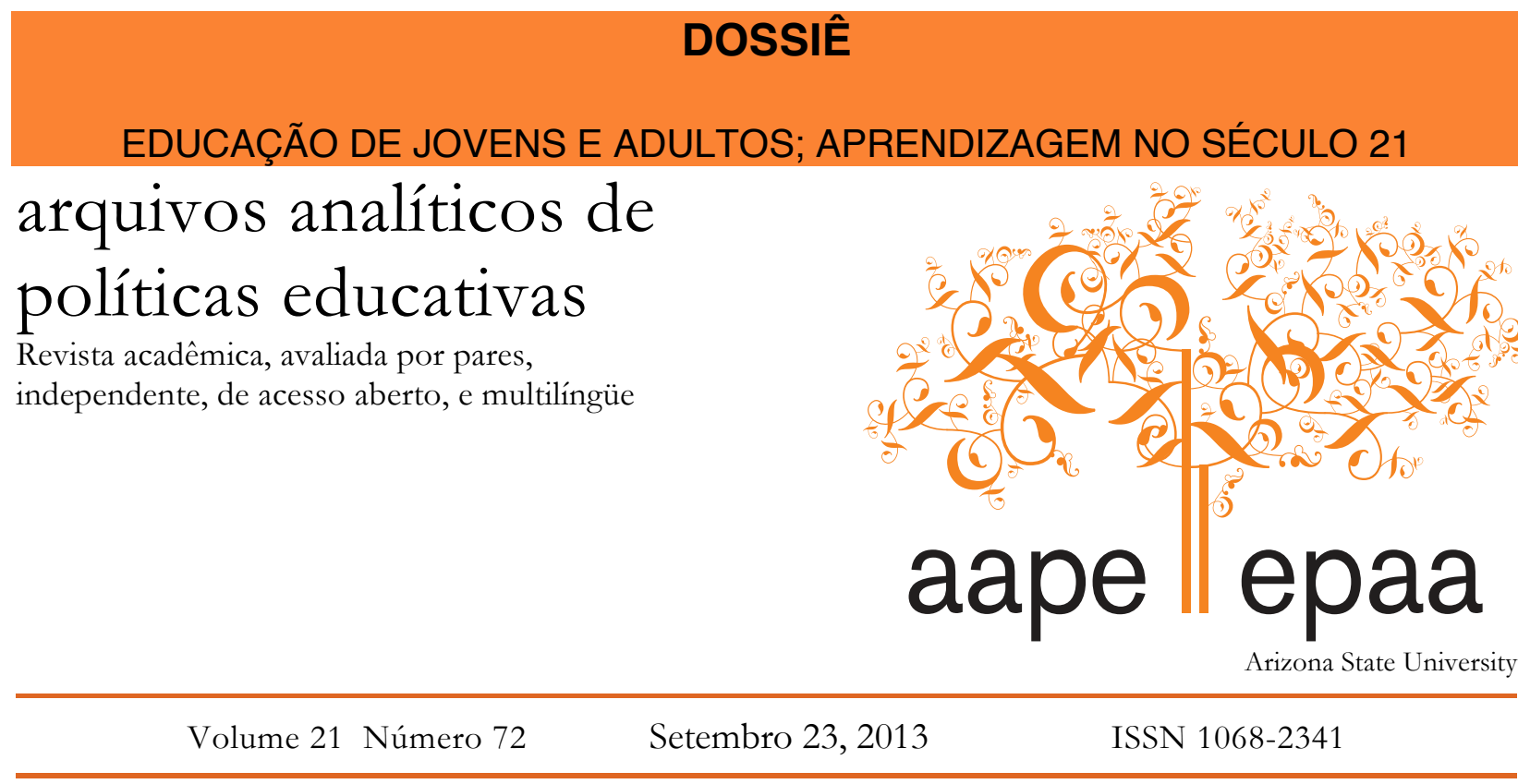

\title{
Mulheres de meios populares e a construção de modos de participação nas culturas do escrito (Minas Gerais, Brasil, século XX)
}

\author{
Ana Maria de Oliveira Galvão \\ Kelly Aparecida de Sousa Queiroz. \\ Mônica Yumi Jinzenji \\ Universidade Federal de Minas Gerais \\ Brasil
}

Citação: de Oliveira Galvão, A.M., De Sousa Queiroz, K. A.. Jinzenji, M. Y. (2013). Mulheres de meios populares e a construção de modos de participação nas culturas do escrito (Minas Gerais, Brasil, Século XX). Arquivos Analíticos de Políticas Educativas, 21(72). Recuperado [data] http://epaa.asu.edu/ojs/article/view/1323. Dossiê Educação de Jovens e Adultos; Editoras convidadas: Sandra Regina Sales \& Jane Paiva

Resumo: Como mulheres de meios populares constroem, ao longo de suas trajetórias de vida, modos de participação nas culturas do escrito? Que instâncias ocupam o papel de "agentes de letramento" nessa participação? Que tipos de participação são construídas? Este artigo busca, com base nos resultados de uma pesquisa concluída, analisar as táticas por meio das quais um grupo de mulheres negras, com experiências restritas ou inexistentes de escolarização, originárias em sua maioria de espaços rurais e atualmente moradoras de um aglomerado em Belo Horizonte, Brasil, construiu sua participação nas culturas do escrito, em meados do século XX. Baseados na metodologia da História Oral, entrevistamos 33 mulheres e realizamos o levantamento de dados secundários de suas localidades de origem. Os pressupostos da história cultural, da sociologia da leitura, e dos trabalhos que discutem as relações entre oralidade e cultura escrita fundamentaram a 
análise dos dados. Os resultados do estudo indicam que a família, a escola, os espaços urbanos e a participação em movimentos sociais foram as principais instâncias que possibilitaram um uso mais efetivo da leitura e da escrita. Mostraram, ainda, que os modos de participação nas culturas do escrito construídos pelas mulheres foram bastante distintos entre si: algumas se tornaram leitoras literárias, escrevem poemas e músicas, desenvolveram uma oralidade extremamente estruturada; a maioria, no entanto, vivencia uma relação de pouca aproximação com o mundo escrito: aprendeu a assinar o nome e desenvolveu táticas para viver em uma sociedade grafocêntrica, como a memorização e o apoio dos que dominam a leitura e a escrita.

Palavras-chave: Brasil; Século XX; Educação de Mulheres; Letramento e Alfabetização de Adultos; História Oral

\section{Low-income women and the construction of ways of participation in written culture (Minas Gerais, Brazil, 20th Century).}

Abstract: How do low-income women build, throughout their lives, ways to participate in written culture? What are the main instances that "sponsor" this participation? What kind of participation is built? This article aims to analyze the tactics through which low-income, uneducated black women, who were born in rural areas and today live in a slum in Belo Horizonte, Minas Gerais, Brazil, built their participation in written culture during the mid-20 $0^{\text {th }}$ century. Oral history was used as methodological approach to interview 33 women. A survey of secondary data about their hometowns was also performed. The theoretical framework includes the works done in the fields of cultural history, sociology of reading, and orality and literacy. The results of the research show that family, school, the urban environment, and the participation in social movements were, in general, responsible for the women's participation in written culture. The research also shows that they performed different ways of participation. Some women became literary readers, wrote poems and music, and developed very organized speeches. However, most of them experienced a distant relationship with the written world: they learned how to sign their names and developed tactics to live in a written-centered society, such as memorization and the help from people who know how to read and write.

Key-words: Brazil; 20 ${ }^{\text {th }}$ Century; Women's Education; Adult Literacy; Oral History

\section{Mujeres de sectores populares y la elaboración de formas de participación en la cultura escrita (Minas Gerais, Brasil, Siglo XX)}

Resumen: ¿Cómo las mujeres de ambientes populares construyen, a través de su trayectoria de la vida, maneras de participación en las culturas de la escritura ¿Qué papel cumplen los "agentes de la alfabetización” en este contexto? ¿Que formas de participación son construidas? Este artículo busca, con base en los resultados de una pesquisa concluida, analizar las tácticas por medio de las cuales un grupo de mujeres negras, con las experiencias restrictas o inexistentes de escolarización, en su mayoría de medios agrícolas y actualmente viviendo en un conglomerado en Belo Horizonte, el Brasil, construyó su participación en las culturas de la escritura, a mediados del siglo XX. Fundamentado en la metodología de la historia oral, entrevistamos a 33 mujeres y levantamos en la reunión de datos secundarios de sus lugares de origen. Estimadas de historia cultural, de la sociología de la lectura, y los trabajos que discuten las relaciones entre la tradición oral y la cultura escrita fundamentaron el análisis de los datos. Los resultados del estudio indican que la familia, la escuela, los espacios urbanos y la participación en movimientos sociales habían sido los principales motivos que hacieron posible un uso más eficaz de la lectura y de la escritura. También mostró, que las formas de participación en las culturas de la escrita construida por las mujeres fueron bastante distintas entre sí: algunas se convirtieron en lectoras literarias, escriben poemas y músicas, desarrollaron una oralidad extremadamente estructurada; la mayoría, sin embargo, vivencia una 
relación de poco acercamiento con el mundo escrito: aprendió a firmar el nombre y desarrolló tácticas para vivir en una sociedad grafo céntrica, como la memorización y la ayuda de los que dominan la lectura y la escritura.

Palabras-clave: Brasil; Siglo XX; Educación de Mujeres; Alfabetización de Adultos; Historia Oral

\section{Introdução}

Como mulheres de meios populares constroem, ao longo de suas trajetórias de vida, modos de participação nas culturas do escrito? Que instâncias ocupam o papel de "agentes de letramento"1 nessa participação? Que tipos de participação são construídas? Este artigo busca, com base nos resultados de uma pesquisa concluída, analisar as táticas ${ }^{2}$ por meio das quais um grupo de mulheres negras, adultas e/ou idosas, com experiências restritas ou inexistentes de escolarização, originárias em sua maioria - de espaços rurais e atualmente moradoras de um aglomerado em Belo Horizonte, capital do estado de Minas Gerais, Brasil, construiu sua participação nas culturas do escrito, em meados do século XX. $\mathrm{Na}$ atualidade, essas mulheres participam de um grupo cultural que busca resgatar músicas e danças tradicionais ${ }^{3}$.

Para a realização da pesquisa, entrevistamos, baseadas nos pressupostos da história oral $^{4}, 33$ mulheres; levantamos dados secundários sobre as suas localidades de origem; e realizamos, durante dois anos e meio, observações sistemáticas do cotidiano das atividades do grupo cultural de que participam atualmente. Utilizamos, para a análise dos dados, os referenciais da história cultural, particularmente da história da leitura e da escrita ${ }^{5}$, da sociologia da leitura ${ }^{6}$, e dos trabalhos que discutem as relações entre oralidade e cultura escrita ${ }^{7}$.

Buscamos compreender de que maneira, em uma sociedade marcada pelo analfabetismo ${ }^{8}$, um determinado grupo social, distanciado das culturas do escrito, construiu modos de participação nessa cultura. Parte-se do pressuposto de que modos de inserção não-escolares, o manuscrito e a oralidade são dimensões constitutivas da cultura escrita no Brasil. Em geral, essas três dimensões tendem a ser desconsideradas por muitas pesquisas, que concentram sua atenção, ao contrário, na

${ }^{1}$ Utilizamos, aqui, a expressão cunhada por (Brandt, 2001, 2007), sponsors of literacy. Para a autora, "sponsors (...) are any agents, local or distant, concrete or abstract, who enable, support, teach, model, as well as recruit, regulate, suppress, or withhold literacy - and gain advantage by in some way." (Brandt, 2007, p.358).

2 Utilizamos tal termo no mesmo sentido que é empregado por De Certeau (1994).

${ }^{3}$ O grupo cultural foi fundado em 1995 por Valentina, uma importante líder comunitária de um aglomerado da região leste de Belo Horizonte. Desde sua origem o grupo é composto por mulheres negras que se encontram na meia-idade e terceira-idade, e hoje conta com 33 membros. Nos últimos anos, ganharam projeção nacional, e têm seu trabalho divulgado constantemente na intensa agenda de apresentações que fazem em cidades de Minas Gerais, de outros estados e países, por meio de turnês (em escolas públicas, em espaços comunitários, em desfiles de moda, em shows próprios e de grupos e cantores que têm visibilidade nacional e internacional). O repertório inclui cantigas de roda, versos e canções próprias e de domínio público. Já gravaram dois CDs próprios e participaram da gravação de CDs e DVDs de outros artistas. São constantemente convidadas a participar de programas de rádio, televisão e eventos culturais. Já foram premiadas por instituições públicas e privadas e objeto de reflexão de alguns trabalhos acadêmicos (Gil, 2008; Galvão et al., 2010). O grupo aparece em reportagens veiculadas em jornais de circulação local e nacional.

4 Ver, entre outros, Amado e Ferreira (1994).

5 Ver, entre outros, Chartier (1994, 1996, 2002) e Hébrard,(1996, 2007).

${ }^{6}$ Ver, entre outros, Lahire (2002, 2004) e De Singly ( 1996).

7 Ver, entre outros, Graff $(1991,1994,2011)$, Scribner \& Cole (1981) e Street (1984).

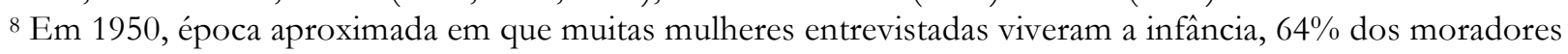
do meio rural de Minas Gerais não sabiam ler nem escrever (IBGE, 1950). 
escolarização como o processo por excelência de entrada nessa cultura, na produção e difusão do impresso como principais evidências de usos da escrita e nas taxas de alfabetização, em contraposição a práticas orais de socialização do escrito, como o indicador privilegiado da existência de usuários da língua escrita.

Mas, afinal, o que é cultura escrita? Certamente, essa não é uma definição simples nem isenta de polêmicas. Neste artigo, assim como em outros trabalhos que temos desenvolvido nos últimos anos, assumimos que, se tomarmos o conceito de cultura em uma acepção antropológica, ou seja, como toda e qualquer produção material e simbólica criada a partir do contato dos seres humanos com a natureza, com os outros seres humanos e com os próprios artefatos criados a partir dessas relações ${ }^{9}$, podemos considerar que a cultura escrita é o lugar - simbólico e material - que o escrito ocupa em/para determinado grupo social, comunidade ou sociedade.

Essa definição traz, de imediato, algumas consequências. A primeira delas diz respeito à compreensão de que a cultura escrita, principalmente em sociedades complexas, não é homogênea ${ }^{10}$. Nesse sentido, temos, em pesquisas realizadas nos últimos anos, preferido utilizar a expressão culturas do escrito $^{11}$. Ela é capaz de expressar que não existe um único lugar para o escrito em uma determinada sociedade ou em determinado grupo social. O uso da palavra "escrito" em lugar de "escrita", por sua vez, serve para destacar que estamos nos referindo não apenas às habilidade de escrever - como se poderia supor, à primeira vista, ao se usar o feminino "escrita" -, mas a todo e qualquer evento ou prática ${ }^{12}$ que tenha como mediação a palavra escrita.

Uma outra consequência da definição acima adotada refere-se ao papel ativo ocupado pelos sujeitos na produção das culturas do escrito. Nesse sentido, é pouco fértil, do ponto de vista da pesquisa, afirmar que os indivíduos e/ou as sociedades entram, se inserem ou têm acesso à cultura escrita. Podemos, no limite, usar esses verbos e/ou expressões para nos referirmos à cultura legítima, para usar uma expressão sistematizada pela sociologia de Pierre Bourdieu ${ }^{13}$. Podemos, também, identificar, nas trajetórias sociais e/ou individuais, alguns momentos que são cruciais nesse processo de participação nas culturas do escrito, como, por exemplo, a introdução da escola em uma comunidade de tradição oral ou a aprendizagem inicial da leitura e da escrita,. Enfim, queremos destacar que os seres humanos produzem cotidianamente bens materiais e simbólicos em várias dimensões de suas vidas e, consequentemente, também em relação ao escrito. Essa produção diária é que vai, ao longo do tempo, configurar o lugar do escrito em seu grupo social, na sua comunidade.

\footnotetext{
${ }_{9}$ Entre as inúmeras definições de cultura utilizadas em estudos realizados no âmbito da Antropologia, recorremos, principalmente às idéias de Clifford Geertz que, por sua vez, se baseia em Max Weber, quando explicita que "o homem é um animal amarrado a teias de significados que ele mesmo teceu, assumo a cultura como sendo essas teias e a sua análise." (Geertz, 1989, p.15). Nessa direção, consideramos que o escrito é parte dessa teia de significados que cada ser humano encontra ao nascer, mas que, simultaneamente, ajuda a tecer.

10 O trabalho de Kalman, (2003) é exemplar nesse sentido. Ao estudar os “escribas” da Praça São Domingo, no México, a autora mostra a diversidade dos usos da leitura e da escrita em uma sociedade complexa.

${ }^{11}$ Ver Galvão (2007). Segundo Chartier (2002), as pesquisas mais recentes sobre o tema, de modo diferente do que faziam os estudos tradicionalmente realizados sobre o tema, buscam não mais compreender a cultura escrita em sua oposição à cultura oral, mas culturas escritas.

12 A distinção entre evento e prática de literacy é discutida, entre outros, por Heath (1983).

13 Para Bourdieu, a cultura dominante ou cultura legítima é o resultado de lutas de poder e concorrência entre diferentes grupos sociais. Para que determinado bem cultural seja considerado legítimo é preciso que ele seja reconhecido por instâncias que têm o poder de arbitrar o que é considerado, por exemplo, "alta cultura" ou "baixa cultura": "Desta forma, para Bourdieu, não há nenhum elemento objetivo que diga que uma cultura é superior às outras, mas sim os valores tácitos atribuídos por certos grupos em posição dominante numa dada configuração social é que fazem dela a cultura legítima" (Cunha, 2007, p.505). Ver Bourdieu (2008).
} 
Ao mesmo tempo, essa configuração é dinâmica, pois os lugares ocupados pelo escrito transformam-se permanentemente: a cada indivíduo que nasce, a cada livro escrito, a cada papel rasgado, a cada tela digitada, a cada poesia recitada ${ }^{14}$. Podemos pensar, então, nessa direção, que, mais do que inserção ou entrada, existem diferentes níveis de produção, de aproximação e de participação de comunidades e de indivíduos nas culturas do escrito.

Por fim, uma última consequência da definição acima merece ser destacada. Na medida em que a cultura escrita diz respeito ao(s) lugar(es) que o escrito ocupa em determinada sociedade, comunidade ou grupo social, reconhecemos, implicitamente, que esses lugares não são os mesmos para os diferentes sujeitos e grupos que vivem naquela sociedade. Em outras palavras, reconhecemos que as culturas do escrito estão inseridas em relações de poder. Essa dimensão tem sido reconhecida, há mais de duas décadas, pelos pesquisadores liderados por Brian Street (1984) que cunhou, ainda nos anos 80, a expressão "modelo ideológico de letramento" (ideological literacy model), para sublinhar que a leitura e a escrita não devem ser compreendidas como um bem em si mesma: os valores que recebem em determinado espaço e tempo somente podem ser dimensionados quando compreendemos as relações de poder que estão na base desses contextos em que são praticadas. Essa concepção se opõe ao que o mesmo autor denominou de "modelo autônomo de letramento", que supõe que a leitura e a escrita sejam valores universais. É fundamental, portanto, para usar novamente expressões da sociologia de Bourdieu (2008), considerar que existem modos de se relacionar com o escrito que são considerados legítimos em determinadas culturas. Por outro lado, é possível encontrar comunidades em que esses modos são ignorados por seus membros e que o escrito não ocupa papel relevante nas hierarquizações simbólicas e sociais que as fundamentam.

A definição acima discutida mostra o quanto a cultura escrita é multifacetada ${ }^{15}$ e de complexa apreensão. Desse modo, destacamos que a compreensão de tal cultura torna-se ainda mais delicada e, em muitos casos, difícil, quando pesquisamos o passado. Diante desse debate é que buscamos compreender as principais instâncias que ocuparam o papel de "agentes de letramento" possibilitando a participação nas culturas do escrito pelas mulheres investigadas - em sua maioria negras, originárias de comunidades rurais e que pouco ou nunca frequentaram a escola.

\section{O Lugar da Família, da Escola e dos Espaços da Cidade na Participação de Mulheres nas Culturas do Escrito}

Os resultados da pesquisa indicam que três instâncias atuaram como "agentes de letramento" nos primeiros anos de socialização das mulheres entrevistadas: a família, a escola e os espaços da cidade.

\section{Família}

De modo geral, as entrevistadas faziam parte de famílias que trabalhavam em terras de terceiros no sistema de "meia"16 ou como arrendatárias ${ }^{17}$ em espaços rurais ${ }^{18}$ de Minas Gerais.

\footnotetext{
${ }^{14}$ Essa questão também foi discutida no artigo já referido (Galvão, 2007).

15 Vale destacar aqui uma expressão de Soares (1985; p.19) quando a referida autora, ainda nos anos 80 - e, portanto, anteriormente à entrada da palavra letramento no Brasil -, analisava "as múltiplas facetas da alfabetização". Quase duas décadas depois, a autora escreveu outro artigo, inspirada no primeiro, em que retoma as várias facetas do letramento (Soares, 2004). Para um aprofundamento nos sentidos que a expressão letramento foi assumindo no Brasil, ver, entre outros, os já clássicos trabalhos de Tfouni (1988) e Kleiman (1995).

${ }^{16}$ Sistema de cultivo da terra na qual o dono fornece o terreno, a casa e, em contrapartida, o meeiro ocupa-se de todo o trabalho e divide o resultado da produção.
} 
Muitas delas, desde os primeiros anos de vida, colaboravam com o trabalho da roça, embora, de modo geral, essa tarefa fosse destinada aos pais e aos irmãos homens. As mães ocupavam-se do serviço doméstico e, eventualmente, também trabalhavam na agricultura. Os pais e as mães das mulheres entrevistadas eram, em sua maioria, analfabetos; encontramos casos, no entanto, em que o pai sabia ler e, em menor número, escrever ${ }^{19}$.

As famílias das entrevistadas eram, em geral, extensas, em uma época em que as taxas de natalidade no Brasil eram altíssimas ${ }^{20}$, assim como as taxas de mortalidade infantil ${ }^{21}$ e de mortalidade materna. Elas tinham, em média, sete irmãos, além daqueles que não sobreviviam ao parto , aos primeiros meses ou anos de vida.

Os modos pelos quais as famílias contribuíram para a participação dessas mulheres nas culturas do escrito podem ser melhor sistematizados ao analisarmos fragmentos dos relatos das entrevistadas referentes ao cotidiano dos primeiros anos de vida. Neles, está presente, por exemplo, a figura do pai que ensinava os(as) filhos(as) a ler, após voltar do serviço na roça, utilizando os materiais de leitura de que dispunha no seu cotidiano, como a Bíblia.

Caso ilustrativo é o de Madalena $(74)^{22}$, cuja família foi responsável pelo ensino da leitura e da escrita. Como era a filha mais velha, nunca frequentou a escola, pois precisava ajudar a mãe nas tarefas domésticas e no cuidado com os irmãos mais novos. Ela narra que o pai e a mãe aprenderam a ler com um professor por eles contratado e reproduziram, com ela, o mesmo procedimento, característico do método sintético, para alfabetizá-la: "catar" as letras e, consecutivamente, as palavras e as frases, em qualquer material escrito que estivesse disponível, com um furo em um papel preparado para esse fim.

A minha mãe, um pouquinho, minha mãe, meu pai, minha mãe que sabia um pouco. Nunca poram eu na escola... Assim, lá naqueles cantão lá da roça, um aprende, um aprende e passa pro outro, não é? (...) É, falava assim, ele falava: "essa é A, A, A, A, A...." Até falar. Aí: "agora é a B". Sabe como é que é? Assim. Meu pai me ensinou foi assim, pra tampar os outro e falar só aquela letra, pra saber. (...) Aprendi assim, entendeu? (...) É, até juntar. Pra juntar uma a uma pra depois... (...) Até juntar uma palavra, né? (Madalena ${ }^{23}$ ).

A escassez de recursos e de acesso a materiais de leitura não era impeditivo para quem "lia o que via pela frente" - de papel catado do chão, embalagem de sabonete, propagandas de arame farpado a revistas Cruzeiro ${ }^{24}$ enviadas por um primo que passou um tempo no Rio de Janeiro, então capital do País, fazendo tratamento de saúde. Seu gosto pela leitura era, no entanto, cerceado, segundo a ideia de que a leitura poderia lhe "estragar o entendimento". Em suas palavras,

Isso mesmo. Isso quando eu tinha oito, dez anos, por aí. E eu lia as coisas que vinha escrito lá, no mundo todo que eles gostavam, mas eu tinha que esconder debaixo do

\footnotetext{
17 Agricultores que alugam a terra dos proprietários, pagando em dinheiro.

${ }^{18}$ Quando adultas, migraram para Belo Horizonte em busca de melhores condições de vida ou para realizarem tratamentos de saúde, estabelecendo residência permanente na capital.

${ }^{19}$ Esses dados são baseados nos relatos das entrevistadas.

${ }^{20}$ Entre 1940 e 1945, a média de filhos por mulher era de 6,4 filhos na zona rural (Camarano \& Beltrão, 2000).

${ }^{21}$ Em 1940, a taxa de mortalidade infantil era estimada em 150 crianças para cada 1.000 nascidos vivos (IBGE, 1999).

22 Em atendimento às exigências éticas da pesquisa, todos os nomes das entrevistadas usados neste artigo são pseudônimos. Ao citar trechos das entrevistas, apresentamos o pseudônimo e a idade da entrevistada na ocasião em que forneceu a entrevista.

${ }^{23}$ Buscou-se preservar, na transcrição das entrevistas, o dialeto utilizado pelas mulheres.

24 Principal revista ilustrada brasileira do século XX, a Cruzeiro circulou entre 1928 e 1975.
} 
travesseiro pra ninguém... Cê já pensou uma pessoa dessa? Eu ter que esconder as palavra, porque "essa menina tá ficando ah... dá um jeito nessa menina! Ela quer ler umas coisas que tá...”, achando que eu tava estragando o entendimento das coisas dela, porque eu queria ir na Lua! (Madalena)

Ainda assim, Madalena tornou-se leitora voraz, já teve poemas publicados, letras de música gravadas, escreveu uma pequena autobiografia e tem vários outros escritos pessoais, reunidos em um caderno.

No caso de algumas mulheres que viviam nos núcleos urbanos, encontramos também casos de pais que ensinavam os(as) filhos(as) a ler; utilizavam-se, no entanto, de uma maior diversidade de materiais escritos. Na família de Cássia (73), cujo pai trabalhava numa pedreira em Belo Horizonte, os jornais e revistas serviram de suporte para o ensino da leitura:

Eu lembro. Ele ensinava a soletrar. (...) É no jornal que ele pegava, jornal. Ele pegava jornal, revista, não sei. Ele comprava caderno, lápis pra gente, tudo direitinho, borracha e... É no jornal que ele pegava as palavrinha... (Cássia)

O pai é citado também como o principal responsável pela possibilidade de votar, quando ser eleitor dependia da capacidade de assinar ${ }^{25}$.

Ele [pai] que me ensinou votar pela primeira vez. Foi ele que me ensinou e tentou, e tentou, até eu conseguir assinar meu nome pra mim tirar o título pra mim votar. Aí ele falou "ô minha filha", fazia pra mim e mandava eu passar por cima o lápis por cima. Aí eu aprendi, passei umas três vez direto e falei "agora eu vou fazer sozinha, eu não vou passar por cima não, uai"... (Palmira, 72)

A imagem do pai escrevendo e lendo cartas para os outros que não sabiam ler nem escrever também compõe um repertório que certamente contribuiu para que a família de algumas mulheres se tornasse uma agência de letramento.

Nos casos em que os pais ou patrões das fazendas contratavam um professor particular para ensinar os filhos, podemos perceber a lógica de funcionamento dessas aulas, que representavam um modo de suprir as necessidades de estudo nas localidades em que não havia a oferta. Como já retratado em outros trabalhos ${ }^{26}$, esses professores eram viajantes que vivia de contratos temporários para ensinar a um grupo de alunos. Eles fixavam-se por alguns meses em certas fazendas e lá ensinavam a ler e a escrever, seguindo adiante para outras regiões onde havia a necessidade de seus serviços. O período de contrato era aparentemente variável, como transparece no depoimento de Basília (75), que se lembra que o professor morou na fazenda entre seis meses a um ano. Em alguns casos, como no caso de Saudade (91), alguns parentes próximos, como o tio materno, exerceram esse papel de professor da família.

No espaço doméstico aconteciam também as contações de histórias e as rodas de música, práticas orais que, certamente, contribuíram para a formação de disposições para a participação em culturas do escrito. O pai, particularmente, aparece como o principal narrador ${ }^{27}$. O tempo da história era associado ao tempo livre, às noites na beira do fogão.

História, nós contava muita história. Aí papai ficava contando pra nós, nós sentava assim na beira do fogo, nós ficava, ficava contando história, eu conheço muita história... A história da Maria de Pau, da Varinha de Condão, entendeu? Do sapo mais o urubu... Amigo da Onça com o Amigo Coelho. Essa eu recordo muito. Da festa no céu. Isso aí parece que todo mundo sabe, só que eles conta ela diferente aqui. (Jacinta, 67)

\footnotetext{
${ }^{25}$ Em 1881, data da denominada lei Saraiva, saber ler e escrever passou a ser condição para votar no Brasil. Somente em 1985, com o fim da ditadura militar, o analfabeto teve reconquistado o direito de voto. 26 Silva (2009) e Rodrigues (1993).

27 Para uma discussão sobre o papel do narrador nas sociedades tradicionais, ver (Benjamin, 1983).
} 
Em muitos casos, ser "criada" 28 por famílias mais abastadas em troca dos serviços domésticos era impeditivo para estudar/continuar os estudos, pois o trabalho passava a ocupar todo o tempo de que dispunham. Por outro lado, algumas mulheres, graças a essa mesma vivência, puderam estudar formalmente, frequentando a escola, ou informalmente, aprendendo com os patrões ou com os filhos deles, embora muitas vezes sem muito sucesso. É o caso de Jacinta :

E eu não tenho paciência. De manhã minha patroa me ensinava, quando era de noite meu patrão me ensinava. Quando ele me ensinava, ele falava "ô Jacinta, o que ocê fez aqui mais a Marisa tá bonito demais, tá certinho. Agora eu tô te ensinando, o trem tá errado" aí eu falo "ah eu acho que eu não tenho cabeça pra isso mais não". Primeiro era meu nome. Ele era doido pra mim assinar o meu nome. Aí eu faço com calma, eu faço, ele, depois eu falo assim "isso aqui tá faltando uns trem que não encaixa na cabeça não". (Jacinta)

Assim, mesmo pertencendo a famílias que tinham no trabalho o eixo do processo de formação dos(s) filhos(as), muitas mulheres entrevistadas vivenciaram, em sua própria casa ou na de outros, processos que lhes permitiram aproximar-se das culturas do escrito.

\section{Escola}

Entre as 22 mulheres originárias do meio rural que foram entrevistadas, 11 frequentaram a escola; entre as cinco que nasceram e cresceram em Belo Horizonte, quatro estudaram em grupos escolares e uma estudou em escola isolada ${ }^{29}$. A oferta de escolarização era, no Brasil dos anos 1940 e 1950, principalmente no meio rural, extremamente restrita.

As memórias sobre as experiências escolares ou a aprendizagem da leitura e da escrita na infância são geralmente traduzidas como tendo sido efêmeras, seguidas do abandono devido à incompatibilidade com o trabalho. Na fala de Eustáquia (59),

Estudei pouco, porque lá, inclusive, nessa fazenda lá tinha uma escola, tipo cês vê hoje mostrando aí na televisão, escola rural, sabe? Vinha menino de longe estudar, mas nós mesmo estudamo pouco, porque não podia, tinha que trabalhar (...) Eu lembro assim, quando a gente podia ir, ia à noite, né? E a luz era lampião, sabe? Mas durante o dia tinha a escola, tinha criança que vinha de longe, sabe? (...) Mas eu pouco aprendi.

O fato de morarem em localidades afastadas que não dispunham de escolas e a necessidade de caminhar longas distâncias somava-se ao intenso ritmo de trabalho, fazendo com que muitas das meninas abandonassem a escola. Segundo Margarida (70),

Tinha escola longe. Era quase mais de légua pra andar pra ir pra escola, mas nós ia todo dia de manhã. Eu frequentei só uns três meses e ela me tirou, por conta do serviço na fazenda, né? (...) e disse que eu não podia estudar mais não, porque eu tinha que trabalhar.

\footnotetext{
${ }^{28}$ A ambivalência da palavra corresponde às vivências de muitas mulheres que estudamos e de parte significativa das mulheres pobres de origem rural brasileiras: elas eram "adotadas" por famílias brancas, de classe média, para auxiliarem (ou serem integralmente responsáveis) pelo serviço doméstico, em troca de casa e de comida, sem direito a salário.

${ }^{29}$ O grupo escolar foi um modelo de escola instituído no Brasil a partir do final do século XIX (e extinto, oficialmente, em 1971), e consistia na reunião, em um mesmo prédio, de diversas aulas que, anteriormente, funcionavam de forma autônoma. Em muitas localidades brasileiras, no entanto, particularmente no meio rural, as escolas continuaram a funcionar em uma única sala de aula, com alunos de diversos níveis de ensino.
} 
Ser menina era um outro fato que, se não impedia o estudo, limitava a permanência na escola, visto que muitas famílias traziam a concepção de que o domínio da escrita pelas filhas podia levá-las a escrever cartas para rapazes. Desse modo, muitas só aprenderam a assinar o próprio nome, como afirma Margarida:

Só aprendi a assinar meu nome. Quando eu comecei a ler alguma coisa, ela me tirou, “"não, cê não pode ler não, porque ocê é muito pra frente, senão cê vai escrever carta à reveria pros outro' e me tirou.

O período de frequência à escola, em geral, não ultrapassava os três primeiros anos do ensino primário. Aquelas que viveram em regiões mais urbanizadas ou em Belo Horizonte estudaram, de modo geral, um ou dois anos a mais. Apenas uma, entre todas as mulheres investigadas, conseguiu, já na idade adulta, concluir o então denominado $2^{\circ} \mathrm{Grau}$, atualmente ensino médio. As escolas rurais e distritais, desde fins do século XIX, tinham a duração de três anos. Somente as escolas reunidas (agrupamento de pelo menos três escolas distritais) e os grupos escolares é que ofereciam o curso primário com duração de quatro anos (Pinho, 2009). Assim, algumas mulheres frequentaram a escola até o limite em que se ofertava nas localidades onde puderam estudar. O pouco tempo que passaram na escola é referido como necessário à aprendizagem do "assinar o nome": habilidade social e simbolicamente relevante quando pensamos que, no período, essa era a condição necessária para votar e para ser publicamente reconhecido como alguém alfabetizado.

Muitas se lembram com saudosismo dos recursos materiais de que dispunham no passado, que já não são mais utilizados na escola e são desconhecidos das novas gerações, como as canetas de pena, os vidros de tinta, as pedras ou lousas pequenas e a tabuada. Poucas delas fazem referência ao uso de livros e cartilhas pelas professoras, mas quando se lembram, citam até mesmo as lições que estudaram, como Eustáquia (59), que se lembra de ter usado uma cartilha do ABC, que "vinha com a historinha de Joãozinho e Maria". Margarida (70) e Benedita (64) utilizaram o livro manuscrito ${ }^{30}$. Benedita cita de cor a lição do "meu sabiá formoso desponta a madrugada, desabrocha a linda rosa esplendorosa...". Glória (66) se lembra de ter estudado a Cartilha da Roça, também bastante utilizada nas escolas rurais.

Para aquelas que estudaram em grupos escolares, a escola foi decisiva para que construíssem uma participação mais efetiva nas culturas do escrito. Para elas, as lembranças reconstruídas remetem à escola dos métodos ativos de ensino, divulgados pelo movimento da Escola Nova ${ }^{31}-$ concretizados no uso do teatro e dos cartazes coloridos -, em convivência com a escola "do passado" - do método individual, dos castigos físicos, da memorização e da repetição. Foi nessa instância que se alfabetizaram e tiveram contato com diversos gêneros textuais e objetos escritos como por exemplo, os poemas, que algumas ainda recitam de cor, os livros didáticos, os livros de literatura e os cartazes ilustrativos das lições.

Seis, entre as 33 entrevistadas, voltaram a frequentar a escola ou frequentaram pela primeira vez quando adultas, após fixarem residência em Belo Horizonte. Seja por incentivo de familiares ou por motivação pessoal, tais iniciativas refletem a importância dada aos estudos formais para obterem melhores condições de vida ou para fugirem do estigma de serem analfabetas. Divina (75) relata o fato de ter feito um outro documento de identidade após ter aprendido a assinar o nome

Porque depois que eu aprendi assinar meu nome. Não, eu tô mentindo; antes deu assinar o nome, eu já votava, ....eu fiz o título, né, quando veio aquela época de fazer

30 Os livros manuscritos, também chamados de paleógrafos, foram impressos no período de 1840 a 1960 no Brasil, por meio da litografia e os caracteres eram "bordados" de modo semelhante à letra cursiva. Para maiores detalhes ver Batista (2009).

31 Para uma análise dos contornos assumidos pelo movimento da Escola Nova em Minas Gerais, ver (Peixoto, 1983). 
o título, sem assinar. (...) aí eu tinha meu título, sabe, que eu não assino,... meu título até hoje,...é que eu não assino, porque... eu não troquei ele não, ele é o mesmo. A identidade também, era que eu não assinava, mas depois eu fiz outra e eu assinei. (Divina)

Emblemático também é o caso de Dolores que, aos 79 anos, concluiu o ensino fundamental, fato ao qual se refere com muito orgulho:

Eu já tô entrando no primeiro grau já, terminando a oitava série. Fim de ano é que vai ser apertado. Tem que estudar. É equação, é História do Brasil, é Geografia também, a gente tem... Ele deu o mapa mundial pra gente.

No ano seguinte, Dolores ingressou no ensino médio.

A análise dos depoimentos referentes às vivências na escola mostra que, embora profundamente desiguais no que se refere ao acesso, aos recursos, à presença de materiais e à eficácia de sua ação, as instituições escolares possibilitaram, de uma maneira ou de outra, uma aproximação dessas mulheres com o mundo da palavra escrita.

\section{Espaços da cidade}

Identificamos, ainda, a inserção no meio urbano como uma forma de contato com "agências de letramento" relevante para a construção de participação nas culturas do escrito.

A maioria das mulheres investigadas é proveniente do interior do estado de Minas Gerais (apenas seis, entre as 33 entrevistadas, nasceu em Belo Horizonte) e morou, durante os primeiros anos de socialização, em sítios próximos a arraiais ou em pequenas comunidades. Apenas algumas delas vivenciaram experiências urbanas na infância. Nesses casos, residiam nos núcleos das municipalidades em que nasceram e/ou cresceram. Nesses pequenos núcleos urbanos, alguns estabelecimentos oficiais pareciam funcionar como instâncias mediadoras entre as comunidades de tradição oral e a circulação de material escrito - como parecem ter sido os casos do cartório e dos correios. Destaca-se o caso de Dinorá (71). Seu padrinho, por quem foi adotada, possuía um cartório nas dependências limítrofes à residência, ambiente também por ela frequentado. Para a entrevistada, o contato com os "papéis" de seu padrinho foram decisivos para que ingressasse na escola "sabendo tudo" e tivesse bom desempenho escolar.

...inclusive já entrei no segundo ano primário, que quando entrei já sabia ler jornal, sabia escrever, inclusive era eu quem fazia trabalho, porque meu padrinho tinha um cartório, escritório dentro de casa que ele era juiz de paz... e o escritório dele era dentro de casa mesmo... então era eu quem separava aqueles coisa... então todo mundo ficava bobo como era esperta.

Nas cidades maiores, particularmente em Belo Horizonte, uma diversidade de equipamentos culturais estavam disponíveis, como o cinema, as bibliotecas, o teatro e a rádio com os seus programas de auditório, o que possibilitava o contato com o escrito, em suas diferentes manifestações.

A gente ia assim, porque antigamente tinha um cinema grátis, eu falava que era cinema grátis. Assim, tipo um telão, mas não era telão, assim na parede. Então tinha um lugar (...) então tinha os dias do homem ia lá passar o filme, e era na parede. Então a gente ficava tudo doido. Era no meio da rua, sabe, eles escolhia um lugar assim. (Neusa, 72)

Brinquei lá no Teatro Francisco Nunes. Brincava na, Teatro Francisco Nunes, Rádio Inconfidência, Rádio Jornal; só gostava de brincar nesses clube assim. $\mathrm{Na}$ rua mesmo eu já não gostava, era só no clube. Ela [a mãe] também não deixava, porque rua era só bagunça. (Glória, 66) 
Nos meios urbanos, havia uma disponibilidade de materiais escritos de forma relativamente ampla, possibilitando que algumas dessas mulheres conhecessem revistas e, particularmente, revistas de fotonovelas, que passaram a circular no Brasil na década de 1940 (Melo, 2010).

Eu tinha coleção de Noturno, tinha coleção de Capricho, tinha coleção de Ilusão... É por isso que eu lia, que eu, que eu lia muito bem, ainda leio um pouco muito bem, porque eu nunca deixei de... Jornal, toda vida eu gostei muito de ler. Nossa Senhora! Eu fazia coleção. Tinha tanta revista, todo mês que eu trabalhava tinha que comprar uma revista diferente. Era Noturno, Ilusão, Capricho, e... Gente, tinha uma outra também que eu fazia coleção. Mac Douglas? Mac Douglas que chamava? Ô gente, era uma revista de ação. Capricho... Eu toda vida fui muito romântica, boba. (Rosa, 63)

Tinha muito livro, muito livro bom. Eu aprendi ler, igual, eu lia livro, mas eu aprendi ler foi leno jornal, revista. Naquela época que usava é, como é que chama? Ah, umas revista que tinha, que tinha aqueles cursos, né? (...) Aí eu comprava aquelas revista pra ler. Então eu aprendi ler foi com revista mesmo, foi na escola não, que na escola eu não me interessei muito não. (Rita, 67)

Destaca-se também, principalmente para as que viveram a infância em bairros centrais de Belo Horizonte, o papel das redes de vizinhança na ampliação de sua participação nas culturas do escrito. Para Valentina (70), liderança comunitária ${ }^{32}$ e fundadora do grupo cultural de que as mulheres entrevistadas atualmente participam, ter sido "criada" por uma família de classe média e branca, que morava na área central de Belo Horizonte, possibilitou que aprendesse a "falar" e a se "comportar" de um modo diferente daqueles que predominavam em seu meio social de origem e ao qual voltou depois de adulta ${ }^{33}$. Possibilitou, também, a convivência com vizinhos que ocupavam posições sociais importantes na cidade na época. Mais do que fornecer os parâmetros da linguagem legítima que ainda hoje são importantes para o exercício de seu papel como liderança comunitária, a vivência em diferentes espaços e lógicas de socialização foram fundamentais para que Valentina ${ }^{34}$ compreendesse como diferenças de classe e de raça/etnia estavam profundamente inscritas na geografia da cidade:

Porque eu, eu tenho duas vivências, né? Eu tenho a vivência do lado dos ricos, e tenho esse lado, então eu posso comparar um com o outro. A minha luta aqui pelo bairro (...) foi justamente por isso, porque eu morei lá, né, na... Onde tinha de tudo. E cheguei aqui, não tinha água, não tinha luz, não tinha ônibus, não tinha nada, eu falei “meu Deus, como que lá tem e aqui não? e o mesmo direito que eles têm nós

32 Valentina trabalhou desde muito jovem em casas de família e, posteriormente, em empresas de limpeza em Belo Horizonte. Foi uma das primeiras moradoras de um aglomerado da região leste da cidade, uma das principais responsáveis pela ocupação e regularização da posse de terra na comunidade e, de modo mais amplo, por seu processo de urbanização. Tornou-se, ao longo do tempo, uma das lideranças comunitárias mais importantes da região. É a fundadora e líder do grupo cultural em questão, do qual participa ativamente, cantando, dançando, tocando instrumentos e coordenando os ensaios. Participa frequentemente de programas de rádio, de televisão, de eventos culturais, políticos e educacionais para falar do grupo e de sua importância como espaço de sociabilidade para mulheres da comunidade.

${ }^{33}$ Heath (1983), em seu estudo etnográfico já clássico, pesquisa detalhadamente os modos como as crianças aprendem a falar em comunidades com distintas lógicas de socialização e como esses diferentes modos têm consequências em suas vivências escolares posteriores.

34 Para uma descrição e análise da história de vida de Valentina, ver (Araújo, 2006). 
também temos aqui". Aí foi que eu comecei a lutar pela melhoria do bairro. Foi essa diferença que me fez começar a luta pela melhoria. Pra vir a água, pra vir a luz, pra vir a rua, aí eu comecei nessa luta tem muito tempo. Por causa dessa diferença. Eu acho que se eu não tivesse morado lá, igual muita gente nasceu aqui, aí não, não tem essa noção... (Valentina)

Por isso, morar na cidade não é garantia por si só de acesso aos equipamentos culturais nela existentes bem como às formas legítimas de usos da leitura e da escrita. As mulheres que moravam em regiões periféricas da capital ${ }^{35}$, como Valentina deixa entrever em seu depoimento, tinham acesso restrito à escolarização, aos materiais impressos e ao lazer.

\section{Considerações Finais}

Destacamos, neste artigo, as principais instâncias de socialização que nos primeiros anos das trajetórias de vida das mulheres investigadas, atuaram como agentes de letramento, proporcionando a participação mais efetiva dessas mulheres nas culturas do escrito. A família - tanto aquela em que havia um esforço sistemático dos pais em ensinar os(as) filhos(as) a ler, como aquela em que as narrativas orais ocupavam as noites à beira do fogão -; a escola por se constituir, muitas vezes, no único espaço de circulação de material escrito nas comunidades em que cresceram - e a vivência em meios urbanos - onde, de modo geral, havia um maior contato e uma maior demanda para os usos da palavra escrita - destacaram-se nesse processo. As configurações que assumiram a família, a escola e a inserção no espaço urbano foram, no entanto, diversas nas trajetórias das mulheres, o que teve implicações nos diferentes (e desiguais) níveis de participação nas culturas do escrito.

Algumas instâncias tradicionalmente identificadas, em outras pesquisas, como responsáveis pelos usos mais efetivos da leitura e da escrita não se mostraram, no presente estudo, importantes nesse processo. Destacamos, aqui, a ausência do trabalho entre esses espaços. As atividades profissionais que as mulheres investigadas ocuparam na vida adulta - depois do trabalho na roça e em serviços domésticos na infância - foram predominantemente de empregada doméstica (16) e de empregadas de serviços gerais em empresas de limpeza (6). Tais funções não exigiam conhecimentos complexos da escrita ${ }^{36}$, e foram por elas desempenhadas sem que houvesse uma demanda para que aprendessem ou desenvolvessem as habilidades de ler e escrever. Os pertencimentos de classe, de gênero e étnico-racial, aos quais essas atividades profissionais estão, no caso brasileiro, intrinsicamente vinculados, tornaram ainda mais difícil a aproximação dessas mulheres com o mundo da palavra escrita.

A participação em atividades religiosas, embora intensa na socialização das mulheres, também não se revelou como um agente significativo de promoção do letramento. Nas memórias das entrevistadas, frequentar a Igreja Católica da comunidade era, principalmente, um momento de sociabilidade, de celebração do encontro ${ }^{37}$. Os rituais religiosos por ela promovidos utilizavam, predominantemente, as linguagens oral e gestual, sem a mediação da palavra escrita.

Os processos de formação, no entanto, são permanentes nas experiências vitais de todos os seres humanos. Nesse sentido, embora não tenhamos nos debruçado sobre outros agentes que, na

\footnotetext{
35 Ver Relatório da Prefeitura de Belo Horizonte, 1937.

36 O estudo de Resende (2008) mostra que, em alguns casos, o trabalho de empregada doméstica, se realizado em lares com ampla circulação de material escrito, pode exercer um papel de importante instância de letramento.

${ }^{37}$ A relação entre catolicismo e cultura escrita é particularmente explorada no estudo de (Souza, 2009) que mostra que, principalmente a partir dos anos 1960, a Igreja Católica torna-se uma instância mais efetiva de promoção do letramento.
} 
idade adulta e/ou na maturidade, também contribuíram para que essas mulheres se aproximassem, de modo mais efetivo, das culturas do escrito, os mencionaremos brevemente aqui, como sinalização para a realização de futuros trabalhos. Na trajetória da maioria das mulheres, a escola permanece como um "agente" do letramento ao longo de suas vidas: como alunas, inicialmente, do MOBRAL ${ }^{38}$ e, posteriormente, da Educação de Jovens e Adultos (EJA); mas principalmente como mães e avós que tiveram/têm que acompanhar a trajetória de escolarização dos filhos e netos.

A inserção nos meios urbanos tornou-se comum a todas as mulheres investigadas a partir da migração para Belo Horizonte, entre as décadas de 1950 e 1960, na maioria dos casos. Embora tenham ido morar, em grande parte dos casos, em aglomerados sem infraestrutura e serviços básicos, viram aumentar, em suas experiências cotidianas, os contatos com materiais escritos e as demandas em torno dos seus usos.

Mesmo que não seja um caso comum, a experiência da fundadora do grupo nos faz destacar o papel que a vivência em movimentos sociais exerce na construção de modos mais efetivos de participação nas culturas do escrito. O contexto em que viveu sua infância - em um bairro central, de classe média, como já nos referimos - criou condições para que, já na década de 1960, aprendesse a lidar com assuntos de natureza jurídica, se vinculasse ao partido comunista e a movimentos sociais relacionados às questões da mulher e do negro. Foi no exercício do papel de liderança comunitária que Valentina, que teve experiências traumáticas em seus quatro anos de escolarização, aprendeu a "falar como um livro".

Finalmente, destacamos aqui a participação do conjunto das mulheres investigadas em um grupo cultural que, com 15 anos de existência, tem hoje reconhecimento nacional. $O$ fato de integrarem esse grupo tem possibilitado outras formas de participação nas culturas do escrito que exigiriam uma análise mais detalhada, que não cabe no escopo deste artigo; apenas as indicaremos aqui. Entre as 33 entrevistadas e componentes, 19 utilizam a leitura das letras das músicas para ensaiá-las e, posteriormente, apresentá-las em shows. É interessante destacar aqui a presença de Verônica que, com quatro anos de escolarização, é a autora de muitas músicas que compõem o repertório do grupo: além de tocar violão, prática que aprendeu com o pai, escreve as letras das músicas e compõe as melodias (sem registrá-las em partituras). Já gravou dois CDs, em parceria com outros artistas da comunidade, interpretando as suas criações.

As demais integrantes do grupo, que não sabem ler, juntam-se, inicialmente, às colegas para escutá-las e, após algumas repetições, guardam as músicas na memória. Em alguns casos, necessitam da ajuda de netos(as) e filhos(as) para auxiliá-las nesse processo. São geralmente essas mulheres que fazem o papel de "jogar versos" nas apresentações, prática de tradição oral que aprenderam ainda na infância em suas comunidades de origem.

Outra atividade envolvida na rotina artística é o fato de as mulheres serem solicitadas a dar autógrafos. Nesses momentos, mesmo aquelas que não sabem escrever ou assinar, desenvolvem táticas para atender a essa demanda. Auxiliadora (72), por exemplo, improvisa uma possível assinatura com as primeiras letras do seu nome e "uns riscos":

Porque faz muita falta assinar meu nome, tem muita coisa aqui que nós chega nesses lugar e precisa de assinar. (...) Eu vou e faço umas três primeiras letras, dou um risco lá, Maria, lá vai embora! "Dá um visto pra nós aqui”... Nós chega nesses lugar até as mulher compra CD e fica mandando nós coisar... dar autógrafo. Eu vou lá e... "Ô Auxiliadora, ocê é danada!" sou mesmo!

\footnotetext{
38 O Movimento Brasileiro de Alfabetização (MOBRAL) foi um programa de alfabetização para adultos criado na ditadura militar brasileira, que funcionou entre 1967 e 1985. Para um estudo crítico sobre o MOBRAL e seus limitados resultados, ver (Paiva, 1981 - 1982).
} 
As mulheres compreendem, desse modo, que o autógrafo não tem uma relação direta com o domínio, em sua dimensão técnica, do escrever. Compreendem, fundamentalmente, as funções sociais e simbólicas da escrita e, desse modo, apreendem que, nesse evento específico de letramento, não dominar a escrita formal não causa, necessariamente, o constrangimento que ocorreria em outras situações diferentes do meio artístico.

Entre a família, a escola, o espaço urbano e a participação em movimentos culturais, sociais e políticos, as mulheres entrevistadas construíram modos de participação nas culturas do escritos bastante distintos entre si. Como analisamos ao longo do artigo, algumas poucas mulheres tornaramse leitoras literárias, escrevem poemas e músicas e desenvolveram um tipo de oralidade extremamente estruturada. A maioria delas, no entanto, vivencia, cotidianamente, uma relação de pouca aproximação com o mundo escrito: aprendeu a assinar (ou a parecer que assina) o nome, lê bilhetes simples, desloca-se pela cidade de forma independente e lida com documentos como por exemplo, receitas médicas e conta ou ainda; acompanha os netos na escola. Ao longo de suas trajetórias de vida, essas mulheres desenvolveram táticas para viver em uma sociedade grafocêntrica, como a memorização e o apoio dos que dominam a leitura e a escrita. Podemos afirmar que suas histórias expressam o modo como a própria história da cultura escrita tem sido construída no Brasil, particularmente por grupos sociais tradicionalmente dela afastados: mulheres, pobres, negras e originárias de comunidades rurais.

\section{Referências}

Amado, J, Ferreira, M. (1994). Usos e Abusos da História Oral. Rio de Janeiro: Fundação Getúlio Vargas.

Araújo, A. D. G. (2006). Território e Trabalho como Possilbilidade de Enraizamento: a História de Valdete do Alto Vera Cruz: Dissertação de Mestrado, Faculdade de Filosofia e Ciências Humanas Universidade Federal de Minas Gerais, Belo Horizonte, Brasil.

Batista, A. A. G. (2009). Dos papéis Velhos aos Manuscritos Impressos: Paleógrafos ou Livros de Leitura Manuscrita. In A. A. G. Batista \& A. M. de O. Galvão (Orgs.), Livros Escolares de Leitura no Brasil: Elementos para uma História (p. 153-178). Campinas: Mercado de Letras.

Benjamin, W. (1983). O Narrador. In: Textos Escolhidos. São Paulo: Câmara Brasileira do Livro.

Bourdieu, P. (2008). A Distinção: Crítica Social do Julgamento. São Paulo: Edusp; Porto Alegre: Zouk.

Brandt, D. (2001). Literacy in American Lives. New York, NY: Cambridge University Press.

Brandt, D. (2007). Sponsors of Literacy. In: GRAFF, Harvey J. (ed.). Literacy and Historical Development: a Reader (p. 357-378). Carbondale, IL: Southern Illinois University.

Camarano, A. A. \& Beltrão, K. I. (2000). Perfil da População Brasileira. Relatório Técnico, IBGE, Rio de Janeiro.

Certeau, M. De. (1994). A Invenção do Cotidiano: Artes de Faz̧er. Petrópolis: Vozes.

Chartier, Roger. (1994). A Ordem dos Livros: Leitores, Autores e Bibliotecas na Europa entre os Séculos XIV e XVIII. Brasília: Editora Universidade de Brasília.

Chartier, R. (1996). Do Livro à Leitura. In: CHARTIER, Roger (org.). Práticas da Leitura (77-105). São Paulo: Estação Liberdade.

Chartier, R. (2002). Os Desafios da Escrita. São Paulo: Editora da Unesp.

Cunha, M. A. De A. O Conceito "Capital Cultural” em Pierre Bourdieu e a Herança Etnográfica. Perspectiva, Florianópolis, v. 25, n. 2, 503-524, jul./dez. 2007.

De Singly, F. (1996). L'Appropriation de l'Heritage Culturel. Lien Social et Politiques (p. 153-165) RIAC. n.35. 
Galvão, A. M. de O. Oralidade, Memória e Narrativa: Elementos para a Construção de uma História da Cultura Escrita. In: Galvão, A. M. de O., et al. (Orgs.). História da Cultura Escrita (p.9-46). Belo Horizonte: Autêntica, 2007.

Galvão, A. M. de O. História das Culturas do Escrito: Tendências e Possibilidades de Pesquisa. In: Marinho, M.; Carvalho, G. T. de. (Org.). Cultura Escrita e Letramento (p. 65-95). Belo Horizonte: Autêntica, 2010,

Galvão, A. M. de O., et al. História de Meninas, Meninas de Sinhá. Belo Horizonte, Duo Editorial, 2010.

Geertz, C. (1989). A Interpretação das Culturas. Rio de Janeiro: Guanabara-Koogan.

Gil, T. N. (2008). Meninas de Sinhá: a Reinvenção da Vida nas Tramas do Discurso Musical. Dissertação de Mestrado, Faculdade de Educação - Universidade Federal de Minas Gerais, Belo Horizonte, Brasil.

Graff, H. J. (1991). The Literacy Myth: Cultural Integration and Social Structure in the Nineteenth Century. 2ed. Brunswick, NJ: Transaction Publishers.

Graff, H. J. (1994). Os Labirintos da Alfabetização. Porto Alegre: Artes Médicas.

Graff, H. (2001). Literacy Myths, Legacies, \& Lessons: New Studies on Literacy. New Brunswick, NY: Transaction Publishers.

Heath, S. B. (1982). What no Bedtime Story Means: Narrative Skills at Home and School. Language in Society, 1, p. 46-79.

Hébrard, J. (1996). O Autodidatismo Exemplar. Como Valentin Jamerey-Duval Aprendeu a Ler? In: Chartier, Roger (org.). Práticas da Leitura (p. 35-74). São Paulo: Estação Liberdade.

Hébrard, J. (2007). Alfabetização e Acesso às Práticas da Cultura Escrita de uma Família do Sul da França entre os Séculos XVIII e XIX: um Estudo de Caso. In: A. M. de O. Galvão, et al. (orgs.). História da Cultura Escrita (p. 48-96). Belo Horizonte: Autêntica.

Instituto Brasileiro de Geografia e Estatística (1954). Censo Demográfico. Série Regional. Vol. XXI, tomo I. Minas Gerais. Rio de Janeiro: Conselho Nacional de Estatística. Serviço Nacional de Recenseamento. Consultado em 06 de maio de 2009, em http://biblioteca.ibge.gov.br/visualizacao/monografias/GEBIS-RJ/CD1950/CD_1950XXI-t1-MG.pdf.

Instituto Brasileiro de Geografia e Estatística (1999). Estudos e Pesquisas. Informação Demográfica e Socioeconômica. Número 2. Evolução e perspectivas da mortalidade infantil no Brasil. Rio de Janeiro: IBGE.

Kalman, J. (2003). Escribir en la Plaza. México: Fondo de Cultura Económica.

Kleiman, A. (Org.) Os Significados do Letramento. Campinas: Mercado de Letras, 1995.

Lahire, B. (2002). Homem Plural: os Determinantes da Ação. Petrópolis: Vozes.

Lahire, B. (2004). Retratos Sociológicos: Disposições e Variações Individuais. Porto Alegre: Artmed.

Melo, J. F. de. (2010). Um Impresso para Mulheres e Seus Modos de Apropriação: a Revista Grande Hotel $e$ Seus Leitores (Belo Horizonte, 1947-1963). Projeto de Doutorado, Faculdade de Educação Universidade Federal de Minas Gerais, Belo Horizonte, Brasil.

Paiva, V. P. (1981- 1982). Mobral: um Desacerto Autoritário I, II e III. Sintese, p. 23-24.

Peixoto, A. C. (1983). Educação no Brasil: Anos Vinte. São Paulo: Loyola.

Pinho, L. A. (2009). Educação e Saúde nos Cursos de Aperfeiçoamento para Professores Rurais - Faz̧enda do Rosário (Minas Gerais, 1947-1956). Dissertação de mestrado, Faculdade de Educação Universidade Federal de Minas Gerais, Belo Horizonte, Brasil.

Prefeitura de Belo Horizonte. Relatório de 1937. Apresentado a S. Excia. O Sr. Governador Benedicto Valladares Ribeiro pelo Prefeito de Bello Horizonte. Belo Horizonte: Graphica Queiroz Breyner LTDA. Consultado em 18/02/2010 em: http://portalpbh.pbh.gov.br/pbh/ecp/comunidade.do?evento=portlet\&pIdPlc=ecpTaxono 
miaMenuPortal\&app $=$ fundacaocultura\&tax $=6762 \& l a n g=p t \_B R \& p g=5520 \& \operatorname{taxp}=0 \& / \mathrm{pbh} /$ contents.do? evento $=$ conteudo\&lang $=\&$ idConteudo $=24201 \& \mathrm{chPlc}=24201$.

Resende, P. C. de. (2008). Modos de Participação de Empregadas Domésticas nas Culturas do Escrito. Dissertação de Mestrado, Faculdade de Educação - Universidade Federal de Minas Gerais, Belo Horizonte, Brasil.

Rodrigues, D. A. (1993). O Significado da Escola Rural Revelado na Trilha do Trabalho. Dissertação de Mestrado, Faculdade de Educação - Universidade Federal de Minas Gerais, Belo Horizonte, Brasil.

Scribner, S. \& Cole, M. (1981). The Psychology of Literacy. Cambridge, MA: Harvard University Press.

Silva, C. M. (2009). Escola, Saberes e Cotidiano no Meio Rural: um Estudo sobre os (as) Jovens do Sertão da Bahia. Dissertação de Mestrado, Faculdade de Educação - Uiversidade de Brasília, Brasília, Brasil.

Soares, M. (2004). Letramento e Alfabetização: as Muitas Facetas. Revista Brasileira de Educação, 25, p. $5-17$.

Soares, M. (1985). As Muitas Facetas da Alfabetização. Cadernos de Pesquisa, 52, p.19-24.

Souza, M. J. F. de. (2009). Modos de Participação nas Culturas do Escrito em uma Comunidade Rural no Norte de Minas Gerais. Tese, Faculdade de Educação - Universidade Federal de Minas Gerais, Belo Horizonte, Brasil.

Street, B. V. (1984). Literacy in Theory and Practice. Cambridge: Cambridge University Press.

Tfouni, L. V. Adultos Não-Alfabetizados: o Avesso do Avesso. Campinas: Pontes, 1988. 


\section{Sobre as Autoras}

\section{Ana Maria de Oliveira Galvão}

Faculdade de Educação, Universidade Federal de Minas Gerais, Brasil

anamgalvao@uol.com.br

Mestra e Doutora em Educação pela Universidade Federal de Minas Gerais, com estágio de pesquisa no Institut National de Recherche Pédagogique, França. Pesquisadora Visitante na Northern Illinois University (2012-2013). Pesquisadora do Conselho Nacional de Desenvolvimento Científico e Tecnológico (CNPq), Brasil. Autora e coautora de diversos livros e capítulos de livros, entre os quais "Cordel: Leitores e Ouvintes" (Autêntica Editora, 2001) e "História de Meninas, Meninas de Sinhá" (Duo Editoral, 2010), e de artigos em periódicos. É professora dos cursos de graduação e pós-graduação da Universidade Federal de Minas Gerais.

\section{Kelly de Sousa Queiroz}

Faculdade de Educação, Universidade Federal de Minas Gerais, Brasil

ksqueiroz@gmail.com

Graduada em Pedagogia pela Universidade Federal de Minas Gerais. É coautora do livro "História de Meninas, Meninas de Sinhá" (Duo Editorial, 2010). É bolsista de projetos de pesquisa na Faculdade de Educação da Universidade Federal de Minas Gerais.

\section{Mônica Yumi Jinzenji}

Faculdade de Educação, Universidade Federal de Minas Gerais, Brasil myjinzenji@gmail.com

Mestra e Doutora em Educação pela Universidade Federal de Minas Gerais, com estágio de pesquisa na University of Michigan. Pós-Doutora pela Universidade Federal de Minas Gerais. Autora e coautora de diversos livros e capítulos de livros, entre os quais "Cultura impressa e educação da mulher no século XIX" (Editora da UFMG, 2010) e "História de Meninas, Meninas de Sinhá" (Duo Editoral, 2010), e de artigos em periódicos. É professora dos cursos de graduação e pós-graduação da Universidade Federal de Minas Gerais.

\section{Sobre as Editoras Convidadas}

\section{Sandra Regina Sales}

Professora do Programa de Pós-Graduação em Educação, Contextos Contemporâneos e Demandas Populares (PPGEduc) na linha de pesquisa Educação e Diversidades Étnico-Raciais e do Departamento Educação e Sociedade da Universidade Federal Rural do Rio de janeiro. sandrasales@,ufrrj.br

A autora é pesquisadora nos campos da Educação de Jovens e Adultos, Mídia e Educação e Políticas de Ação Afirmativa no Ensino Superior. Integra o Grupo de Pesquisa (CNPq) Políticas de transformação: pesquisas em educaşão e comunicação, do qual é líder, e o Laboratório de Estudos Afro-brasileiros LEAFRO. Atualmente desenvolve as pesquisas $A$ EJ $A$ e a diversidade na mídia: uma análise das representaçoes dos sujeitos, dos atores e das políticas educacionais nas revistas semanais brasileiras e Que educação para que cidadão? Discursos influentes na Educação de Jovens e Adultos no Brasil (1995-2013). É coorganizadora do livro Educação de Jovens e Adultos: políticas e práticas educativas (2011) e tem publicado artigos em revistas e capítulos de livros nas áreas de pesquisa nas quais atua. 


\section{Jane Paiva}

Professora do Programa de Pós-Graduação em Educação (ProPEd), na Linha de Pesquisa Educação Inclusiva e Processos Educacionais e do Curso de Pedagogia da Faculdade de Educação da Universidade do Estado do Rio de Janeiro (UERJ).

janepaiva@terra.com.br

A autora é pesquisadora no campo da educação de jovens e adultos, atuando na formação de pedagogos e de novos pesquisadores - mestres e doutores. É líder do Grupo de Pesquisa (CNPq) Aprendizados ao longo da vida: sujeitos, politicas e processos educativos. No momento desenvolve a pesquisa integrada (com a Universidade Estadual de Campinas e a Universidade Federal de Juiz de Fora) Diagnóstico da qualidade de ensino na educação de jovens e adultos: um estudo de caso nos municipios de Campinas, Juiz de Fora e Rio de Janeiro, financiada pelo Edital Observatório da Educação, da CAPES/INEP; e coordena as ações do projeto de pesquisa e extensão do Centro de Referência e Memória da Educação Popular e da Educação de Jovens e Adultos (CReMEJA). Autora de artigos em revistas e capítulos de livros no campo.

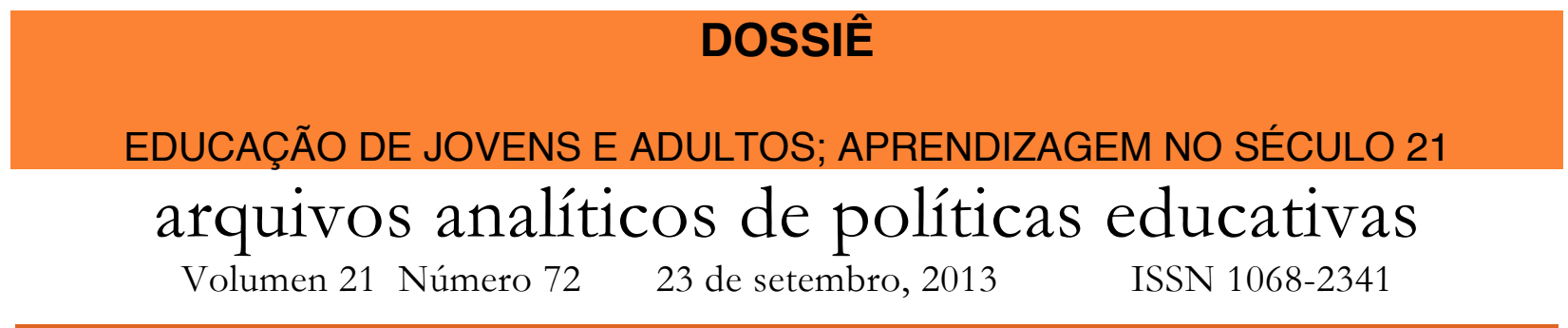

\section{(c)}

SORERIGHISRESERVED O Copyright e retido pelo/a o autor/a (ou primeiro co-autor) que outorga o direito da primeira publicação à revista Arquivos Analíticos de Políticas Educativas. Más informação da licença de Creative Commons encontram-se em http://creativecommons.org/licenses/by-nc-nd/2.5. Qualquer outro uso deve ser aprovado em conjunto pelo/s autor/es e por AAPE/EPAA. AAPE/EPAA é publicada por Mary Lou Fulton Institute Teachers College da Arizona State University. Os textos publicados em AAPE são indexados por CIRC (Clasificación Integrada de Revistas Científicas, Espanha) DIALNET (Espanha),Directory of Open Access Journals, Education Full Text (H.W. Wilson), EBSCO Education Research Complete, , ERIC, , QUALIS A2 (Brasil), SCImago Journal Rank; SCOPUS, SOCOLAR (China). Contribua com comentários e sugestões a http://epaa.info/wordpress/ ou para Gustavo E. Fischman fischman@asu.edu.

Curta a nossa comunidade EPAA's Facebook https://www.facebook.com/EPAAAAPE e Twitter feed@epaa_aape. 


\section{arquivos analíticos de políticas educativas conselho editorial}

Editor: Gustavo E. Fischman (Arizona State University) Editores Associados: Rosa Maria Bueno Fisher e Luis A. Gandin

(Universidade Federal do Rio Grande do Sul)

Dalila Andrade de Oliveira Universidade Federal de Minas Gerais, Brasil

Paulo Carrano Universidade Federal Fluminense, Brasil

Alicia Maria Catalano de Bonamino Pontificia Universidade Católica-Rio, Brasil

Fabiana de Amorim Marcello Universidade Luterana do Brasil, Canoas, Brasil

Alexandre Fernandez Vaz Universidade Federal de Santa Catarina, Brasil

Gaudêncio Frigotto Universidade do Estado do Rio de Janeiro, Brasil

Alfredo M Gomes Universidade Federal de Pernambuco, Brasil

Petronilha Beatriz Gonçalves e Silva Universidade Federal de São Carlos, Brasil

Nadja Herman Pontificia Universidade Católica -Rio Grande do Sul, Brasil

José Machado Pais Instituto de Ciências Sociais da Universidade de Lisboa, Portugal

Wenceslao Machado de Oliveira Jr. Universidade Estadual de Campinas, Brasil
Jefferson Mainardes Universidade Estadual de Ponta Grossa, Brasil

Luciano Mendes de Faria Filho Universidade Federal de Minas Gerais, Brasil

Lia Raquel Moreira Oliveira Universidade do Minho, Portugal

Belmira Oliveira Bueno Universidade de São Paulo, Brasil

António Teodoro Universidade Lusófona, Portugal

Pia L. Wong California State University Sacramento, U.S.A

Sandra Regina Sales Universidade Federal Rural do Rio de Janeiro, Brasil

Elba Siqueira Sá Barreto Fundação Carlos Chagas, Brasil

Manuela Terrasêca Universidade do Porto, Portugal

Robert Verhine Universidade Federal da Bahia, Brasil

Antônio A. S. Zuin Universidade Federal de São Carlos, Brasil 


\section{education policy analysis archives editorial board}

Editor Gustavo E. Fischman (Arizona State University)

Associate Editors: Audrey Amrein-Beardsley (Arizona State University), Rick Mintrop, (University of California, Jeanne M. Powers (Arizona State University)

Jessica Allen University of Colorado, Boulder

Gary Anderson New York University

Michael W. Apple University of Wisconsin, Madison

Angela Arzubiaga Arizona State University

David C. Berliner Arizona State University

Robert Bickel Marshall University

Henry Braun Boston College

Eric Camburn University of Wisconsin, Madison

Wendy C. Chi* University of Colorado, Boulder

Casey Cobb University of Connecticut

Arnold Danzig Arizona State University

Antonia Darder University of Illinois, UrbanaChampaign

Linda Darling-Hammond Stanford University

Chad d'Entremont Strategies for Children

John Diamond Harvard University

Tara Donahue Learning Point Associates

Sherman Dorn University of South Florida

Christopher Joseph Frey Bowling Green State University

Melissa Lynn Freeman* Adams State College

Amy Garrett Dikkers University of Minnesota

Gene V Glass Arizona State University

Ronald Glass University of California, Santa Cruz

Harvey Goldstein Bristol University

Jacob P. K. Gross Indiana University

Eric M. Haas WestEd

Kimberly Joy Howard* University of Southern California

Aimee Howley Ohio University

Craig Howley Ohio University

Steve Klees University of Maryland

Jaekyung Lee SUNY Buffalo
Christopher Lubienski University of Illinois, UrbanaChampaign

Sarah Lubienski University of Illinois, UrbanaChampaign

Samuel R. Lucas University of California, Berkeley

Maria Martinez-Coslo University of Texas, Arlington

William Mathis University of Colorado, Boulder

Tristan McCowan Institute of Education, London

Heinrich Mintrop University of California, Berkeley

Michele S. Moses University of Colorado, Boulder

Julianne Moss University of Melbourne

Sharon Nichols University of Texas, San Antonio

Noga O'Connor University of Iowa

João Paraskveva University of Massachusetts, Dartmouth

Laurence Parker University of Illinois, UrbanaChampaign

Susan L. Robertson Bristol University

John Rogers University of California, Los Angeles

A. G. Rud Purdue University

Felicia C. Sanders The Pennsylvania State University Janelle Scott University of California, Berkeley

Kimberly Scott Arizona State University

Dorothy Shipps Baruch College/CUNY

Maria Teresa Tatto Michigan State University

Larisa Warhol University of Connecticut

Cally Waite Social Science Research Council

John Weathers University of Colorado, Colorado Springs

Kevin Welner University of Colorado, Boulder

Ed Wiley University of Colorado, Boulder

Terrence G. Wiley Arizona State University

John Willinsky Stanford University

Kyo Yamashiro University of California, Los Angeles

* Members of the New Scholars Board 


\section{archivos analíticos de políticas educativas consejo editorial}

Editor: Gustavo E. Fischman (Arizona State University)

Editores. Asociados Alejandro Canales (UNAM) y Jesús Romero Morante (Universidad de Cantabria)

Armando Alcántara Santuario Instituto de Investigaciones sobre la Universidad y la Educación, UNAM México

Claudio Almonacid Universidad Metropolitana de Ciencias de la Educación, Chile

Pilar Arnaiz Sánchez Universidad de Murcia, España

Xavier Besalú Costa Universitat de Girona, España Jose Joaquin Brunner Universidad Diego Portales, Chile

Damián Canales Sánchez Instituto Nacional para la Evaluación de la Educación, México

María Caridad García Universidad Católica del Norte, Chile

Raimundo Cuesta Fernández IES Fray Luis de León, España

Marco Antonio Delgado Fuentes Universidad Iberoamericana, México

Inés Dussel FLACSO, Argentina

Rafael Feito Alonso Universidad Complutense de Madrid, España

Pedro Flores Crespo Universidad Iberoamericana, México

Verónica García Martínez Universidad Juárez Autónoma de Tabasco, México

Francisco F. García Pérez Universidad de Sevilla, España

Edna Luna Serrano Universidad Autónoma de Baja California, México

Alma Maldonado Departamento de Investigaciones Educativas, Centro de Investigación y de Estudios Avanzados, México

Alejandro Márquez Jiménez Instituto de Investigaciones sobre la Universidad y la Educación, UNAM México

José Felipe Martínez Fernández University of California Los Angeles, USA
Fanni Muñoz Pontificia Universidad Católica de Perú

Imanol Ordorika Instituto de Investigaciones Economicas - UNAM, México

Maria Cristina Parra Sandoval Universidad de Zulia, Venezuela

Miguel A. Pereyra Universidad de Granada, España

Monica Pini Universidad Nacional de San Martín, Argentina

Paula Razquin UNESCO, Francia

Ignacio Rivas Flores Universidad de Málaga, España

Daniel Schugurensky Arizona State University

Orlando Pulido Chaves Universidad Pedagógica Nacional, Colombia

José Gregorio Rodríguez Universidad Nacional de Colombia

Miriam Rodríguez Vargas Universidad Autónoma de Tamaulipas, México

Mario Rueda Beltrán Instituto de Investigaciones sobre la Universidad y la Educación, UNAM México

José Luis San Fabián Maroto Universidad de Oviedo, España

Yengny Marisol Silva Laya Universidad Iberoamericana, México

Aida Terrón Bañuelos Universidad de Oviedo, España

Jurjo Torres Santomé Universidad de la Coruña, España

Antoni Verger Planells University of Amsterdam, Holanda

Mario Yapu Universidad Para la Investigación Estratégica, Bolivia 